\section{Sticky Materials}

While one is sitting in the dentist's chair, it is not possible to talk, so one has to think. During a recent visit to have a crown fitted, I started musing on adhesives. My dentist had used one adhesive to fit the temporary crown and a second to fix the permanent prosthesis. The first lasted two weeks and came off cleanly with a flick of her toothpick, while the second will (I hope) stay put for many years while permitting me to eat toffee.

This is one example of the many uses of adhesives that we tend to take for granted. They are widely used in manufacturing. Superglue is used to join skin after surgery, and the story of the Post-it note is a classic which I will not repeat here. Is this widespread set of applications reflected in, or supported by, serious research and teaching? I am sure it must be, but where? I searched unsuccessfully for a Materials Research Society symposium on adhesives, and I have trawled the Web looking for evidence that anyone, anywhere, teaches the science or technology of adhesives to materials students...but I found very little.

Entering "sticky materials" into my favorite search engine, I received over 300,000 hits, including one for "sticky dentistry"! And my non-Web browsing over four recent conferences has unearthed lots of fascinating material-so here are some examples for someone more energetic than I to incorporate in a new module, course, or grant proposal.

Let's start with the Great Wall of China. It might not be the only object on Earth visible from the moon but is it, as I was assured recently by a reputable scientist, held together with tapioca? I can find no basis for this tale, but tapioca is made from cassava, and wood glues made from cassava starch have been in use for thousands of years.

Moving on from botany to zoology, I notice that geckos (which walk with apparent ease across walls and ceilings) have provided the inspiration for a range of synthetic adhesives that, like Velcro and Post-it notes, can be attached and reattached many times. Perhaps Spider-man is to become reality sooner than we expected.

Human physiology provides more serious illustrations of the importance of adhesion and sticky properties: There is increasing evidence that the stickiness of $\beta$-amyloid protein fragments contributes to the development of Alzheimer's disease because the fragments cluster together into fibrils and eventually into plaques in the brain. Diseased red blood cells also appear to be stickier than their healthy counterparts, and this contributes to illnesses such as malaria.

\section{Does anyone yet have a funded project \\ to work on the adhesive that lime trees deposit on parked cars?}

Materials scientists are involved in research in all these topics, but I am not sure that they are covering the whole range of possibilities. Does anyone yet have a funded project to work on the adhesive that lime trees deposit on parked cars? Or the shear strength of the bond between shoe, spilt orange juice, and kitchen floor? Or the peel strength of book pages stuck together with jam? In The Times, I read that a professor from Bristol has been funded to develop chewing gum that can be easily removed from the underside of a student desk or a city sidewalk. He has developed the non-sticky gum, but not yet the flavoring, so I do not expect initial sales to be high. My own city of Liverpool has called for a special tax on gum to fund the recurrent cleanup operations, but the Bristol solution

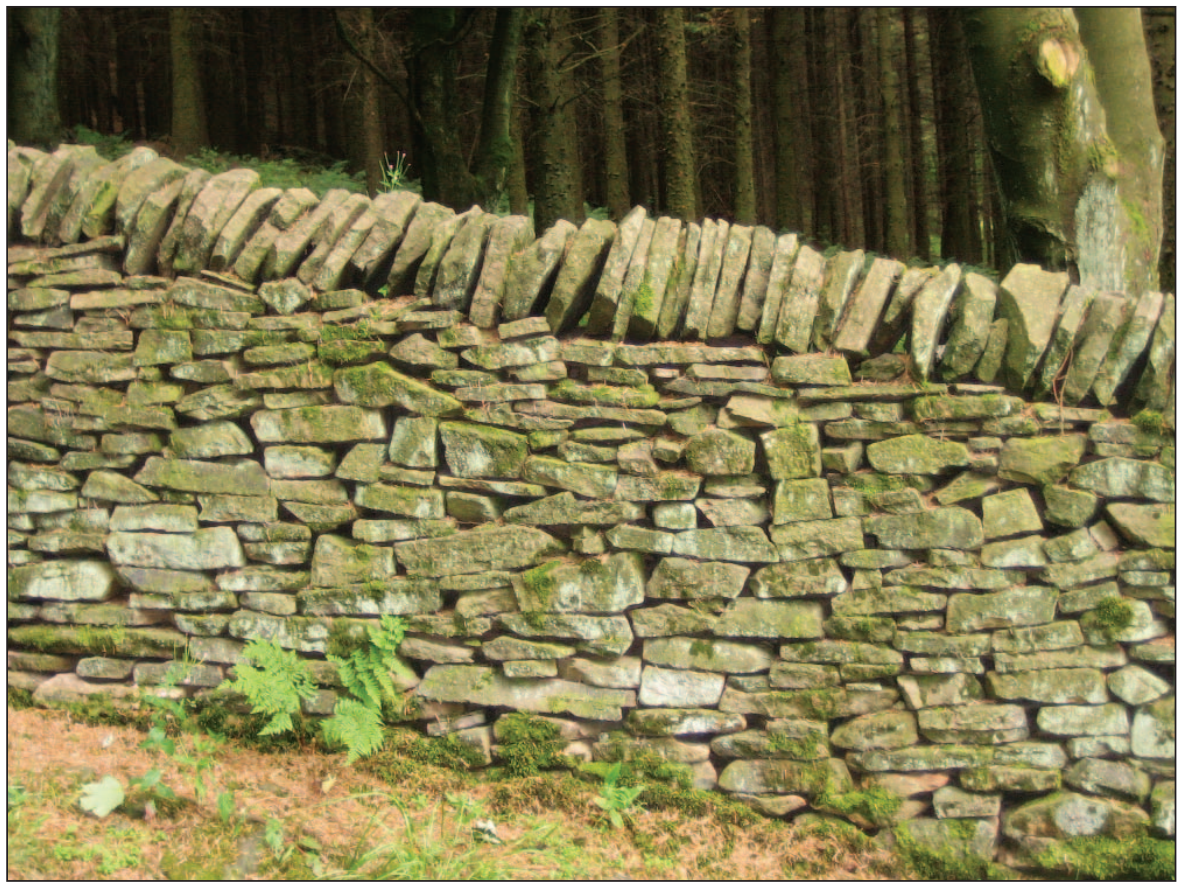

A dry stone wall in Derbyshire, England. Courtesy of Peter Goodhew.

seems more likely to be successful. I cannot wait-I ruined a pair of trousers by sitting on a still-warm piece of gum only last month.

A further rich seam of research opportunities is staring at you each morning at breakfast. I am sure you do not do this, but if you were to leave your morning bowl of cereal unwashed until the evening, you would have encountered, stuck to the now-dry bowl, the most robust and tenacious adhesive known to Homo domesticus. My candidate for best performer is a cereal regularly available in the United Kingdom called Weetabix. However, any oat- or corn-based cereal will do. Perhaps we can get both a research grant and material for an undergraduate course on adhesives out of this.

Finally it occurs to me, in the very best tradition of dispassionate academic debate and against my own best interests as a grant-seeker, that the most elegant solution to many problems is not to use any adhesive at all. Newton's bridge at Cambridge (allegedly) and any decent arch with a keystone have no need of adhesives. My own part of England is riddled with dry stone walls, which also contain no adhesive at all. (But if they fall down, I bet Weetabix would be good to mend them.)

PETER GOODHEW 